\title{
Characterization of the anticancer effects of S115, a novel heteroaromatic thiosemicarbazone compound, in vitro and in vivo
}

\author{
Min-yu LIU ${ }^{1,2}$, Lin XIAO², Yu-qiong DONG ${ }^{3}$, Ying LIU², Li CAI ${ }^{2}$, Wei-xia XIONG², Yu-long YAO², Ming YIN, *, Quan-hai LIU², * \\ ${ }^{1}$ School of Pharmacy, Shanghai Jiao Tong University, Shanghai 200240, China; ${ }^{2}$ Department of Pharmacology, Shanghai Institute of \\ Pharmaceutical Industry, Shanghai 200437, China; ${ }^{3}$ Shanghai Kairun Bio Pharm Company, Ltd, Shanghai 201108, China
}

\begin{abstract}
Aim: To investigate the anticancer effects of S115, a novel heteroaromatic thiosemicarbazone compound in vitro and in vivo. Methods: The anti-proliferative action of S115 was analyzed in 12 human and mouse cancer cell lines using MTT assay. Autograft and xenograft cancer models were made by subcutaneous inoculation of cancer cells into mice or nude mice. The mice were orally treated with S115 $\left(2,8,32 \mathrm{mg} \cdot \mathrm{kg}^{-1} \cdot \mathrm{d}^{-1}\right)$ for $7 \mathrm{~d}$, and the tumor size was measured every $3 \mathrm{~d}$. Cell apoptosis and cell cycle distribution were examined using flow cytometry, gene expression profile analyses, Western blots and RT-PCR.

Results: The $\mathrm{IC}_{50}$ values of $\mathrm{S} 115$ against 12 human and mouse cancer cell lines ranged from 0.3 to $6.6 \mu \mathrm{mol} / \mathrm{L}$. The tumor growth inhibition rate caused by oral administration of $\mathrm{S} 115\left(32 \mathrm{mg} \mathrm{kg}^{-1} \cdot \mathrm{d}^{-1}\right)$ were $89.7 \%, 81.7 \%, 78.4 \%$ and $77.8 \%$, respectively, in mouse model of B16 melanoma, mouse model of Colon 26 colon cancer, nude mouse model of A549 lung cancer and nude mouse model of SK-OV-3 ovarian cancer. Furthermore, oral administration of $\mathrm{S} 115\left(7.5 \mathrm{mg} \cdot \mathrm{kg}^{-1} \cdot \mathrm{d}^{-1}\right)$ synergistically enhanced the anticancer effects of cyclophosphamide, cisplatin, or 5-fluorouracil in mouse model of S180 sarcoma. Treatment of A549 human lung cancer cells with $\mathrm{S} 115(1.5 \mu \mathrm{mol} / \mathrm{L})$ induced $\mathrm{G}_{0} / \mathrm{G}_{1}$ cell cycle arrest, and increased apoptosis. Furthermore, $\mathrm{S} 115$ downregulated the level of ubiquitin, and upregulated the level of Tob2 in A549 cells.

Conclusion: S115 exerts anticancer effects against a variety of cancer cells in vitro and in grafted cancer models by inducing apoptosis, downregulating ubiquitin and upregulating Tob2.
\end{abstract}

Keywords: anticancer drug; thiourea; thiosemicarbazone; melanoma; colon cancer; human lung cancer; ovarian cancer; cell cycle arrest; apoptosis; ubiquitin; Tob2

Acta Pharmacologica Sinica (2014) 35: 1302-1310; doi: 10.1038/aps.2014.71; published online 15 Sep 2014

\section{Introduction}

Chemotherapy is still an important option for cancer treatment despite the availability of surgery and irradiation. However, the use of available chemotherapeutic agents is often restricted, mainly due to severe side effects and tumor resistance. The successful chemotherapeutic treatment of cancer, therefore, remains a challenge in this century, and this clearly indicates the urgent need for developing new and safe chemotherapeutic drugs with more potent anticancer activity.

Thiourea derivatives represent one of the promising classes of anticancer drugs that have a variety of activities against various leukemias and solid tumors. These compounds were first synthesized at the beginning of the twentieth century.

\footnotetext{
* To whom correspondence should be addressed.

E-mail liuquanhai_Iqh@163.com (Quan-hai LIU); myin@sjtu.edu.cn (Ming YIN)

Received 2014-03-06 Accepted 2014-06-25
}

For decades, these compounds have been used to adjust plant growth $^{[1]}$ and to produce herbicides ${ }^{[2]}$, insecticides ${ }^{[3]}$, chelating metal ions ${ }^{[4]}$, other organic catalysts of chiral synthesis ${ }^{[5]}$, and rubber vulcanization accelerators ${ }^{[6]}$. Some of these thiourea derivative compounds have also been reported to have pharmaceutical potential as anti-bacterial ${ }^{[7]}$, anti-fungal ${ }^{[8]}$, antitubercular ${ }^{[9]}$, anticancer ${ }^{[10]}$, and anti-HIV ${ }^{[11]}$ agents.

Recently, special attention has been given to pyridyl, bispyridyl, benzoylpyridyl, and isatin thiosemicarbazone derivatives that exhibit significant anticancer, antiviral and other activities in free and in metal-complexed forms. This key biological role is often related with their capability to inhibit the enzyme, ribonucleotide reductase, similar to what is observed with potent anticancer drugs such as Triapine ${ }^{[12]}$. In the anticancer drug field, numerous research studies have been performed, mainly involving the modification of structures and activity tests. The mechanisms by which these compounds exert their anticancer effects also include inhibitory activity 
against protein tyrosine kinase ${ }^{[13]}$, human sirtuin type proteins 1 and $2^{[14]}$, topoisomerase II and DNA repair synthesis ${ }^{[15,16]}$. For these reasons, thiourea derivatives are promising potential candidates of anticancer drugs. In vivo analysis indicates that some thiosemicarbazones show potential as chemotherapeutic agents. Further work is needed for these compounds to be approved as drugs. Here, we report a newly synthesized heteroaromatic thiosemicarbazone compound, S115, that possesses potent anticancer effects in vitro and in vivo.

\section{Materials and methods Drugs and reagents}

S115 was obtained from Sundia Meditech Company Ltd, Shanghai, China (Figure 1). Its molecular weight of $290 \mathrm{Da}$ and $99.9 \%$ purity were confirmed by NMR spectrometry and HPLC. Cyclophosphamide (CTX), 5-fluorouracil (5-Fu), and cisplatin were obtained from Jiang Su Heng Rui Medicine Co, Ltd, Shanghai Xudong Haipu Pharmaceutical Co, Ltd, and Qilu Pharmaceutical Co, Ltd, respectively. All the drugs were freshly dissolved in sterile, normal saline solution. Dimethyl sulfoxide (DMSO) and thiazolyl blue tetrazolium bromide (MTT) were purchased from Sigma-Aldrich (St Louis, MO, USA).

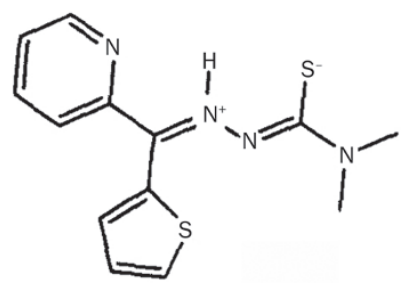

Figure 1. Chemical structure of S115.

\section{Cell lines and cell culture}

All human and mouse tumor cell lines were obtained from the Cell Bank of the Chinese Academy of Sciences, Shanghai, China. A549 and NCI-H460 human lung cancers, SK-OV-3 human ovarian cancers, MCF-7 and Bcap-37 human breast cancers, BGC-823 human gastric carcinoma, QGY-7701 human hepatoma, A431 human epithelial carcinoma, A375 and K111 human and mouse melanoma cells were grown in DMEM medium supplemented with heat-inactivated fetal bovine serum and $2 \mathrm{mmol} / \mathrm{L}$ L-glutamine. K562 and L1210 human and mouse leukemia cells were grown in RPMI-1640 medium supplemented with $10 \%$ heat-inactivated fetal bovine serum and $2 \mathrm{mmol} / \mathrm{L}$ L-glutamine. All of the cell lines were grown at $37^{\circ} \mathrm{C}$ in a humidified atmosphere containing $5 \% \mathrm{CO}_{2}$. The cells $\left(5 \times 10^{4}\right)$ were placed in 6-well plates and cultured for $24 \mathrm{~h}$. They were then treated with $1.0 \mu \mathrm{mol} / \mathrm{L} \mathrm{S115}$ for $6,12,24$, and $48 \mathrm{~h}$.

\section{Cell growth inhibition assay}

Cellular anti-proliferative assays were carried out using the (3-[4,5-dimethyl-2-thiazolyl]-2,5-diphenyl-2H-tetrazolium bro- mide, MTT) assay. After treatment for 48 h, $20 \mu \mathrm{L}$ MTT solution $(5 \mathrm{mg} / \mathrm{mL})$ was added to each well. Four hours later, the supernatant was removed and $100 \mu \mathrm{L}$ DMSO was added per well. Absorbance at $492 \mathrm{~nm}$ was determined using a microplate reader (Bio-Rad Inc, Hercules, CA, USA) and the $\mathrm{IC}_{50}$ values were calculated. All the experiments were repeated three times.

\section{Experimental animals}

Female C57BL/ 6 mice, BALB/c mice, and BALB/c nude mice, aged 6 to 8 weeks, were purchased from the Shanghai Laboratory Animal Center (Shanghai, China). After shipment, the mice were housed in a temperature- and humidity-controlled, specific-pathogen-free environment with a 12-h light/dark cycle (lights on at 7:00 AM) for 3-7 d and allowed to acclimatize before the experiment. The animals were given food and distilled water ad libitum. All the animal studies were approved by the Shanghai Institute of Pharmaceutical Industry Animal Care and Use Committee.

\section{Tumor inoculation}

The allograft and xenograft cancer models were established by subcutaneous inoculation of 5 million mouse melanoma (B16) cells, mouse colon cancer (Colon26) cells, human lung cancer (A549) cells, or human ovarian cancer (SK-OV-3) cells into the flanks of C57BL/6 mice, BALB/c mice, and BALB/c nude mice. The mice were randomly allocated to control and treatment groups, and were administered oral saline $(25 \mathrm{~mL} / \mathrm{kg})$ or S115 at 2, 8, and $32 \mathrm{mg} / \mathrm{kg}$ for $7 \mathrm{~d}$ starting on the day after subcutaneous inoculation in allograft models or when the tumors reached approximately $100 \mathrm{~mm}^{3}$ in xenograft models. The tumor length and width were measured every $3 \mathrm{~d}$, and the tumor volume was calculated with the following formula: volume $=D \times d^{2} \times n / 6$. At the end of the experiments, tumorbearing animals were killed with $\mathrm{CO}_{2}$ asphyxiation, and the tumors were isolated and weighed.

The $Q$ value was calculated with the following formula: $E_{\mathrm{a}+\mathrm{b}} /\left(E_{\mathrm{a}}+E_{\mathrm{b}}-E_{\mathrm{a}} \times E_{\mathrm{b}}\right)^{[17]}$. $E_{\mathrm{a}+\mathrm{b}}$ is the rate of inhibition of concomitant medications, and $E_{\mathrm{a}}$ and $E_{\mathrm{b}}$ are the rates of inhibition of the drugs $\mathrm{A}$ and $\mathrm{B}$, respectively. In this way, the $Q$ value of 0.85-1.15 indicates additive ( + ) in the inhibition, and $>1.15$ indicates synergistic $(++)$ in the inhibition. The results are expressed as the mean $\pm S D$, and the statistical significance was evaluated using a one-way analysis of variance (ANOVA). The results were considered statistically significant at $P$ values of 0.05 .

\section{Cell cycle analysis and apoptosis analysis}

For the apoptosis assay, the cultured cells were harvested and fixed overnight with $70 \%$ ethanol at $-20^{\circ} \mathrm{C}$. The cellular DNA was stained with $100 \mathrm{mg} / \mathrm{mL}$ propidium iodide and 100 $\mathrm{mg} / \mathrm{mL}$ RNase A in PBS. The flow cytometric analysis was performed to assess the cell cycle distribution with a FACSCalibur Flow Cytometer (Becton Dickinson, Franklin Lakes, NJ, USA). Data were analyzed with FlowJo software (Tree Star, Ashland, OR, USA). 


\section{Gene expression analysis}

An Affymetrix Gene Chip Human Genome U133 Plus 2.0 Array (containing 47000 transcripts, representing 38500 human genes) was used to detect the gene expression profiles of the human non-small cell lung carcinoma A549 cells, under the action of $0.5 \mathrm{\mu mol} / \mathrm{L} \mathrm{S115}$ at $0,3,6,9,12,24$, and $48 \mathrm{~h}$, with 3 chips per point in time. Slides were scanned using a GeneChip® Scanner 3000 (Affymetrix, Santa Clara, CA, USA) and Command Console Software 3.1 (Affymetrix, Santa Clara, CA, USA) with default settings. Raw data were normalized using a MAS 5.0 algorithm and Gene Spring Software 11.0 (Agilent Technologies, Santa Clara, CA, USA). The expression profiles were analyzed and differentially expressed genes were organized into gene network pathways using the Genespring software package (Agilent Technologies, Santa Clara, CA, USA).

\section{Western blot analysis}

For Western blotting, Tob2 antibody binding was visualized using a horseradish peroxidase-conjugated secondary antibody and a DAB detection system. The bands were scanned using an image scanning densitometer (Tanon Science \& Technology Co, Shanghai, China).

\section{Real-time PCR}

The primer concentrations were normalized and the genespecific forward and reverse primers were mixed. Both the primers were present in the mixture at a concentration of 5 pmol $/ \mu L$. The real-time PCR reaction mixture had a final volume of $20 \mu \mathrm{L}$. The following mixture was prepared in each tube [10 $\mu \mathrm{L}$ SYBR Green Mix $(2 \times) ; 1 \mu \mathrm{L}$ liver cDNA; 1 $\mu \mathrm{L}$ primer pair mix (5 pmol/ $\mu \mathrm{L}$ of each primer); $7.6 \mu \mathrm{L} \mathrm{H}_{2} \mathrm{O}$ ]. The experiment was set up using the following PCR program on an ABI 7500: initial denaturation at $95^{\circ} \mathrm{C}$ for $15 \mathrm{~s}$, followed by 40 cycles of denaturation at $95^{\circ} \mathrm{C}$ for $5 \mathrm{~s}$ and annealing at $>60^{\circ} \mathrm{C}$ for $34 \mathrm{~s}$.

\section{Results}

\section{Anti-proliferative activity in vitro}

To assess the activity of S115, the anti-proliferative effect of S115 for a panel of 10 human and mouse cancer cell lines were examined. After $48 \mathrm{~h}$ of treatment, S115 broadly reduced the cell viability in all the cancer cells in a concentration-dependent manner. The calculated $\mathrm{IC}_{50}$ values of S115 ranged from
0.3 to $6.6 \mu \mathrm{mol} / \mathrm{L}$ (Table 1 ). The anti-proliferative effects of S115 appeared to have no tissue specificity or species specificity.

Table 1. Antiproliferative effects of $\mathrm{S} 115$ on human and mouse cancer cell lines. Cell growth was measured using a MTT assay and half inhibitory concentration $\left(\mathrm{IC}_{50}\right)$ values were calculated.

\begin{tabular}{lllr}
\hline & & Cell line & $\begin{array}{r}I_{50} \pm \text { SD } \\
(\mu \mathrm{mol} / \mathrm{L})\end{array}$ \\
\hline Human & Lung cancer & A549 & $1.2 \pm 0.7$ \\
& Ovarian cancer & NCI-H460 & $2.9 \pm 1.1$ \\
& Breast cancer & SK-OV-3 & $6.3 \pm 2.2$ \\
& GCF-7 & $0.5 \pm 0.4$ \\
& Gastric carcinoma & Bcap-37 & $1.5 \pm 0.9$ \\
& Hepatoma & BGC-823 & $6.6 \pm 3.5$ \\
& Epithelial carcinoma & QGY-7701 & $1.0 \pm 0.6$ \\
& Melanoma & A331 & $3.5 \pm 1.1$ \\
& Leukemia & K562 & $2.4 \pm 1.6$ \\
& Vascular endothelial cells & HUVEC & $2.5 \pm 1.7$ \\
& Leukemia & L1210 & $0.8 \pm 4.8$ \\
Mouse & Melanoma & K111 & $1.2 \pm 0.9$ \\
& Fibroblasts & $3 T 3$ & $10.3 \pm 5.9$ \\
Chinese hamster & Lung fibroblasts & CHL & $14.2 \pm 8.8$ \\
& Ovary & CHO & $12.5 \pm 9.1$ \\
\hline
\end{tabular}

\section{Anticancer effects in vivo}

The anticancer effects of S115 were further evaluated in mouse melanoma (B16), mouse colon cancer (colon26) allograft models, human lung cancer (A549), and human ovarian cancer (SK-OV-3) xenograft models.

In the mouse melanoma model, S115 did not significantly reduce the body weight relative to the mice treated with saline (Table 2). At the end of the experiment, the isolated tumor weight was $3.96 \pm 0.31 \mathrm{~g}$, which was significantly inhibited in a dose-dependent manner by $44.0 \%, 65.8 \%$, and $81.8 \%$ (Figure 2A, Table 3).

In the mouse colon model, S115 did not significantly reduce the body weight relative to the mice treated with saline (Table 2 ). At the end of the experiment, the isolated tumor weight was $3.81 \pm 0.22 \mathrm{~g}$. $\mathrm{S} 115\left(2,8\right.$, and $\left.32 \mathrm{mg} \cdot \mathrm{kg}^{-1} \cdot \mathrm{d}^{-1}\right)$ significantly inhibited the tumor growth in a dose-dependent manner at

Table 2. Average body weights were quantified when tumors were excised from allografted C57BL/6 mice on d 10 after $7 \mathrm{~d}$ of treatment with increasing doses of $\mathrm{S} 115$

\begin{tabular}{lcccc}
\hline \multirow{2}{*}{ Group } & \multicolumn{2}{c}{ Colon26-BALB/c mouse model } & \multicolumn{2}{c}{ B16-C57BL/6 mouse model } \\
& D 0 & Body weight (g) & D 0 & D 10 \\
\hline Saline $(20 \mathrm{~mL} / \mathrm{kg})$ & $17.62 \pm 0.39$ & $21.84 \pm 0.64$ & $17.78 \pm 0.37$ & $22.05 \pm 1.14$ \\
S115 $(2 \mathrm{mg} / \mathrm{kg})$ & $17.75 \pm 0.43$ & $21.49 \pm 0.76$ & $17.82 \pm 0.69$ & $21.84 \pm 0.87$ \\
S115 $(8 \mathrm{mg} / \mathrm{kg})$ & $17.83 \pm 0.35$ & $20.29 \pm 0.60$ & $18.15 \pm 0.29$ & $21.22 \pm 1.05$ \\
S115 (32 mg/kg) & $17.91 \pm 0.18$ & $20.20 \pm 1.79$ & $17.75 \pm 0.38$ & $21.33 \pm 1.00$ \\
\hline
\end{tabular}


A

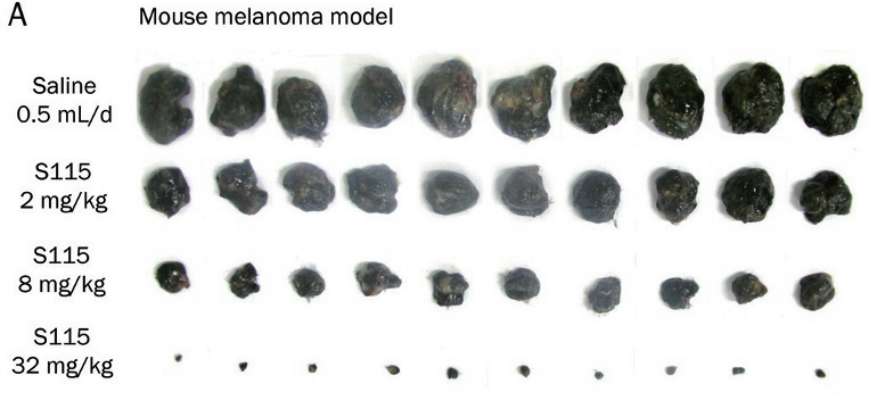

B

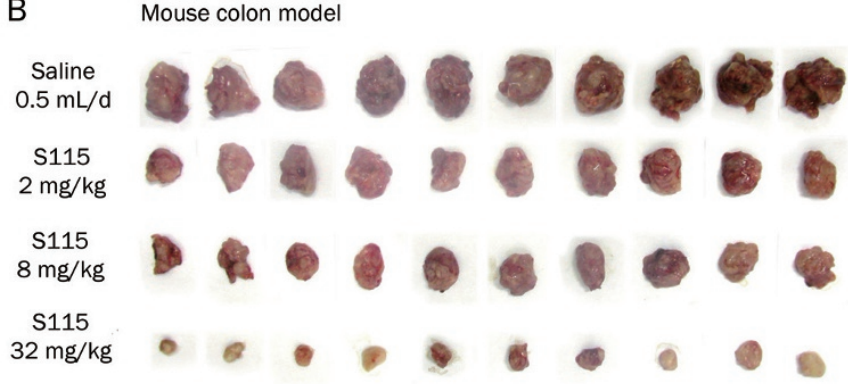

Figure 2. Inhibitory effects of multi-daily gavage of S115 on B16 (A) and Colon26 (B) tumor growth in the allografted B16-C57BL/6 or BALB/C mouse model. B16 mouse melanoma cells or Colon2 6 colon cells were injected into $\mathrm{C} 57 \mathrm{BL} / 6$ or BALB/c mice. Immediately after inoculation, mice were given multi-daily gavage of saline $(0.5 \mathrm{~mL} / \mathrm{d})$ or $\mathrm{S} 115(2,8$, or $32 \mathrm{mg} \cdot \mathrm{kg}^{-1} \cdot \mathrm{d}^{-1}$ ) for $7 \mathrm{~d}$. Images of the excised B16 tumors from all mice in each group are shown. Data are presented as mean \pm SD. $(n=10$ in each group).

the inhibition rates of $42.0 \%, 64.6 \%$, and $79.0 \%$, respectively (Figure 2B, Table 3).

In the human lung cancer model (A549), tumors in the control group grew exponentially and the tumor volume increased from $46 \pm 5.9 \mathrm{~mm}^{3}$ to $1361 \pm 95.8 \mathrm{~mm}^{3}$. Multi-daily gavage of $\mathrm{S} 115\left(2,8\right.$, and $\left.32 \mathrm{mg} \cdot \mathrm{kg}^{-1} \cdot \mathrm{d}^{-1}\right)$ inhibited the tumor growth in a dose-dependent manner by $42.4 \%, 59.1 \%$, and $78.4 \%$, respectively (Figure 3A). The anticancer effect of S115 was also confirmed in the weight of the tumors isolated from the nude mice at the end of the experiment (Figure 3B).
Table 3. Inhibitory effects of multi-daily gavage of $\mathrm{S} 115$ on Colon26 or B16 tumor growth in the allografted BALB/C mouse or B16-C57BL/6 mouse model. Average tumor weights were quantified for tumors excised from allografted models on $\mathrm{d} 10$ after $7 \mathrm{~d}$ of treatment with increasing doses of $\mathrm{S} 115 .{ }^{\mathrm{c}} P<0.01$ vs saline.

\begin{tabular}{|c|c|c|c|c|}
\hline \multirow{2}{*}{ Group } & \multicolumn{2}{|c|}{$\begin{array}{c}\text { Colon26-BALB/c } \\
\text { mouse model }\end{array}$} & \multicolumn{2}{|c|}{$\begin{array}{l}\text { B16-C57BL/6 } \\
\text { mouse model }\end{array}$} \\
\hline & $\begin{array}{c}\text { Tumor } \\
\text { weight (g) }\end{array}$ & $\begin{array}{c}\% \\
\text { Inhibition }\end{array}$ & $\begin{array}{c}\text { Tumor } \\
\text { weight (g) }\end{array}$ & $\begin{array}{c}\% \\
\text { Inhibition }\end{array}$ \\
\hline Saline (20 mL/kg) & $3.69 \pm 0.31$ & & $3.81 \pm 0.22$ & \\
\hline $\mathrm{S} 115$ (2 mg/kg) & $2.14 \pm 0.11^{\mathrm{c}}$ & 42.0 & $2.13 \pm 0.09^{c}$ & 44.0 \\
\hline $\mathrm{S} 115$ (8 mg/kg) & $1.31 \pm 0.14^{c}$ & 64.6 & $1.30 \pm 0.07^{c}$ & 65.8 \\
\hline $\mathrm{S} 115$ (32 mg/kg) & $0.78 \pm 0.20^{\circ}$ & 79.0 & $0.70 \pm 0.15^{c}$ & 81.8 \\
\hline
\end{tabular}

In a nude mouse model of ovarian cancer, SK-OV-3, tumors in the control group increased in size from $103 \pm 6.1$ to $2148 \pm 48.3 \mathrm{~mm}^{3}$. Multi-daily gavage of $\operatorname{S115}(2,8$, and 32 $\mathrm{mg} \cdot \mathrm{kg}^{-1} \cdot \mathrm{d}^{-1}$ ) inhibited the tumor growth in a dose-dependent manner. The inhibition rates at the end of the experiment were $41.4 \%, 67.1 \%$, and $77.8 \%$, respectively (Figure $4 \mathrm{~A}$ ). The anticancer effect of S115 was also confirmed in the weight of the tumors isolated from the nude mice at the end of the experiment (Figure 4B).

In the Bcap-37 human breast cancer model, tumors in the control group grew exponentially and the tumor volume increased from $50 \pm 1.3 \mathrm{~mm}^{3}$ to $1634 \pm 169.9 \mathrm{~mm}^{3}$. Multi-daily gavage of $\mathrm{S} 115\left(2,8\right.$, and $\left.32 \mathrm{mg} \cdot \mathrm{kg}^{-1} \cdot \mathrm{d}^{-1}\right)$ inhibited the tumor growth in a dose-dependent manner by $46.6 \%, 68.3 \%$, and $79.5 \%$, respectively (Figure 5A). The anticancer effect of S115 was also confirmed in the weight of the tumors isolated from the nude mice at the end of the experiment (Figure 5B).

Synergistic anticancer effects of S115 with cyclophosphamide, 5-fluorouracil, and cisplatin

To assess the synergistic anticancer effects of S115 with cyclophosphamide, 5-fluorouracil, and cisplatin, the experiments were performed in an S180 sarcoma model in ICR mice.

The treatment with S115, CTX, Pt, or 5-Fu alone, was found

Table 4. Synergistic anti-tumor effects of multi-daily administration of S115 $\left(7.5 \mathrm{mg} \cdot \mathrm{kg}^{-1} \cdot \mathrm{d}^{-1}\right.$, gavage) with cyclophosphamide $\left(C T X, 15 \mathrm{mg} \cdot \mathrm{kg}^{-1} \cdot \mathrm{d}^{-1}\right.$, intravenously), cisplatin (Pt, $1 \mathrm{mg} \cdot \mathrm{kg}^{-1} \cdot \mathrm{d}^{-1}$, intravenously) or 5-fluorouracil (5-Fu, $12.5 \mathrm{mg} \cdot \mathrm{kg}^{-1} \cdot \mathrm{d}^{-1}$, intravenously) in the allografted S180-ICR mouse model ( $n=10$ per group).

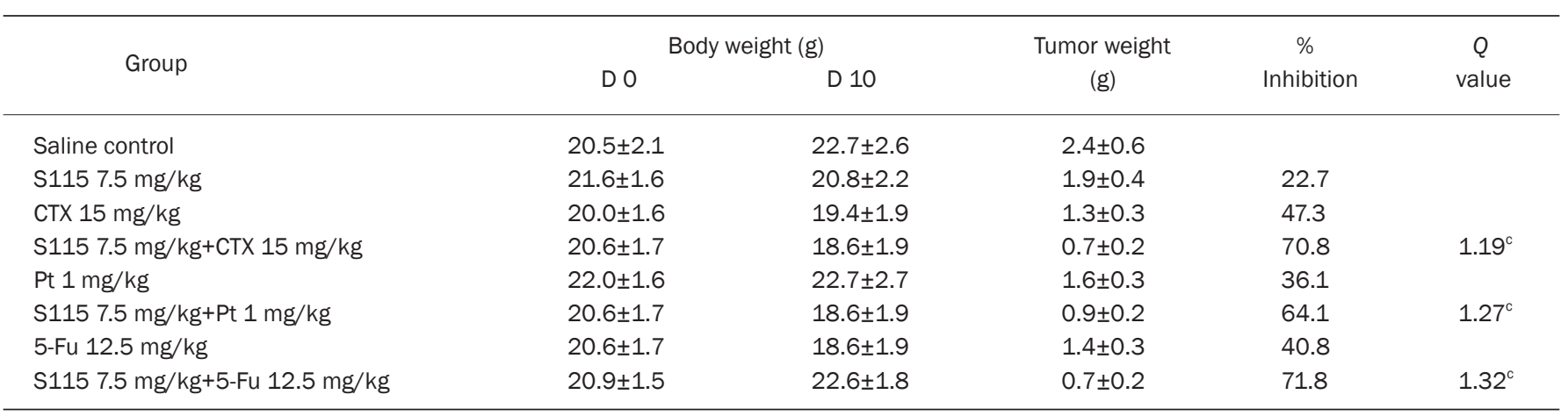


A

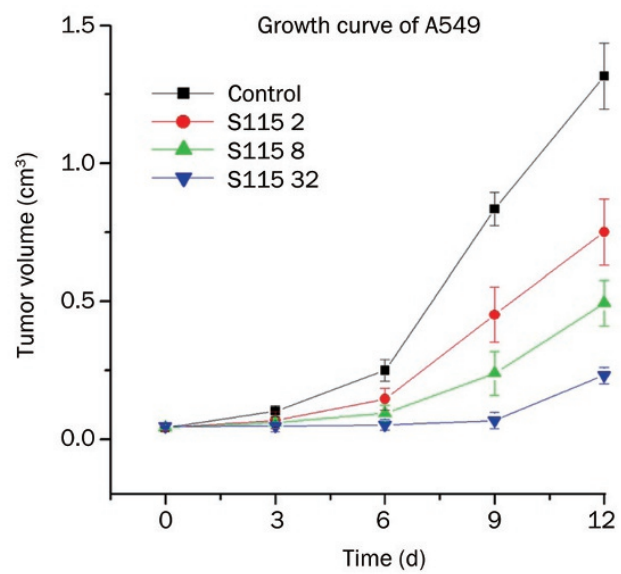

B

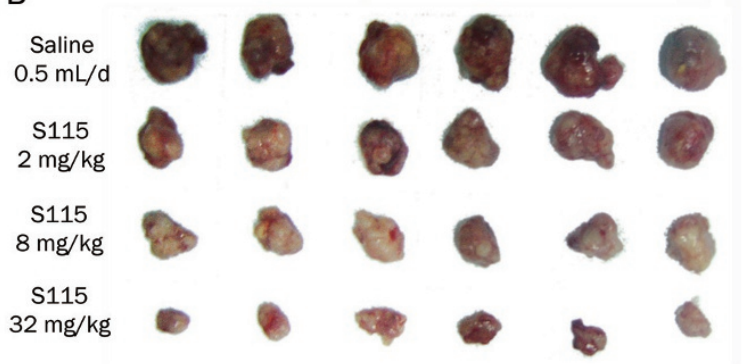

Figure 3. Inhibitory effects of multi-daily gavage of S115 on A549 tumor growth in the xenografted A549-BALB/c nude mouse model. A549 human lung carcinoma cells were injected into BALB/c nude mice. After solid tumors grew to about $100 \mathrm{~mm}^{3}$, mice were given multi-daily gavage of saline $(0.5 \mathrm{~mL} / \mathrm{d})$ or $\mathrm{S} 115\left(2,8\right.$, or $\left.32 \mathrm{mg} \cdot \mathrm{kg}^{-1} \cdot \mathrm{d}^{-1}\right)$ for $7 \mathrm{~d}$. (A) Tumor growth is shown as measured by tumor volume over a time-course. (B) Images are shown for the isolated tumors from the mice from each group following $12 \mathrm{~d}$ treatment. Data are presented as mean \pm SD. $n=6$ per group.

to inhibit the tumor growth by $22.7 \%, 47.3 \%, 36.1 \%$, and $40.8 \%$, whereas the co-treatment of S115 with CTX, Pt, or 5 -Fu inhibited the tumor growth by $70.8 \%, 64.1 \%$, and $71.8 \%$, respectively. The interaction $Q$ values indicated that $S 115$ has a synergistic anticancer effect with CTX, Pt, and 5-Fu (Table 4).

\section{S115 induces cell cycle arrest at the $G_{0} / G_{1}$ phase}

S115-induced apoptosis was confirmed in human lung cancer (A549) cells through flow cytometry. The progression of the cell cycle was studied and a significant accumulation of cells was observed in the $G_{0} / G_{1}$ phase (Figure 6). The DNA content and the cell cycle of A549 cells were found to change markedly under the influence of S115. Cells were blocked by S115 during the $\mathrm{G}_{0}-\mathrm{G}_{1}$ transition and the number of apoptotic cells increased over time.

S115 affects the expression of the ubiquitin-proteasome system (UPS)-related genes.

Real-time quantitative PCR was used to confirm the results of the microarray (Figure 7). The expression profiles were analyzed, and differentially expressed genes were organized
A

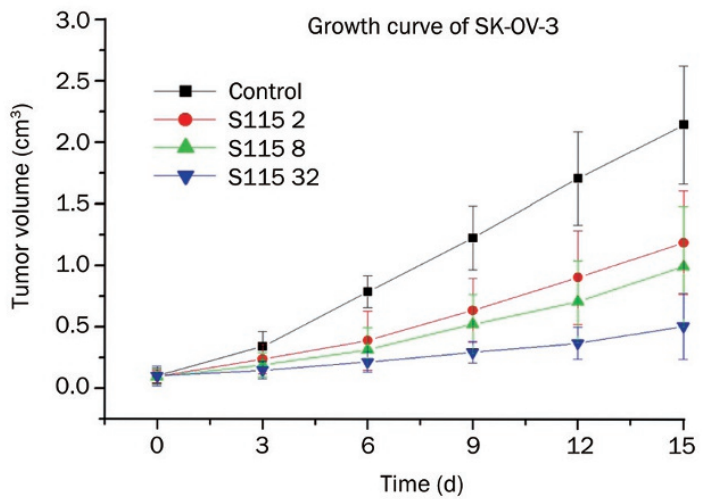

B

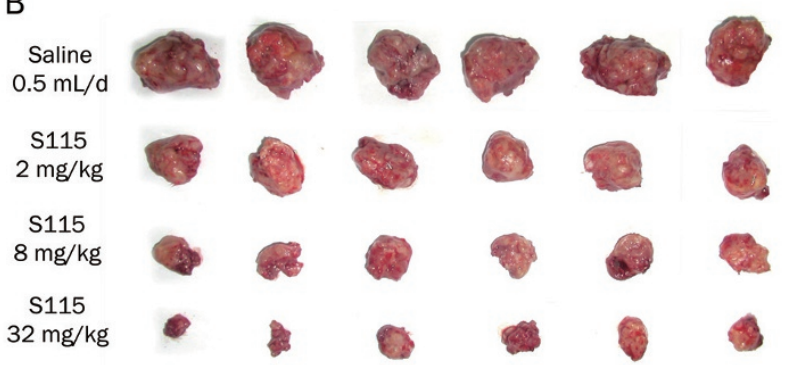

Figure 4. Inhibitory effects of multi-daily gavage of S115 on SK-OV-3 tumor growth in xenografted SK-OV-3-BALB/C nude mouse model. SKOV-3 human hepatoma cells were injected into BALB/c nude mice. After solid tumors grew to about $100 \mathrm{~mm}^{3}$, mice were given multi-daily gavage of saline $(0.5 \mathrm{~mL} / \mathrm{d})$ or $\mathrm{S} 115(2,8$, or $32 \mathrm{mg} / \mathrm{kg})$ for $7 \mathrm{~d}$. (A) Tumor growth was measured by tumor volume and is graphed over time. (B) Images are isolated tumors from the mice from each group after $12 \mathrm{~d}$ of treatment. Data are presented as mean \pm SD. $n=6$ per group.

into gene network pathways using Genespring software (Agilent Technologies). S115 induced apoptosis in human lung cancer (A549) cells. Differentially expressed genes included those involved in the UPS (Figure 8). S115 downregulated the expression of ubiquitin and upregulated Tob2 expression (Figure 7).

\section{Discussion}

Thiourea compounds have been widely applied in fields such as medicine and the pharmaceutical sciences. There have been many reports on the synthesis, structure-activity relationship, and the anticancer effects of these compounds. Several complexes, including thiourea-platinum ${ }^{[18]},-\operatorname{gold}^{[19]},-$-iron $^{[20]}$, and -copper ${ }^{[21]}$, have been synthesized. Thiourea derivatives of classic anticancer drugs such as camptothecin ${ }^{[22]}$ and podophyllum ${ }^{[23]}$ have also been synthesized and tested for the anticancer activities. In recent years, the successful development of target-specific compounds received widespread recognition for their utility in clinical treatment. The derivatives of thiourea and thiosemicarbazone with these target-specific compounds such as vascular endothelial growth factor receptor (VEGFR) ${ }^{[24]}$, endothelial growth factor receptor (EGFR) ${ }^{[25]}$, platelet-derived growth factor receptor (PDGFR) ${ }^{[26]}$, and insulin-like growth factor receptor (IGFR) ${ }^{[27]}$ are also notable 
A

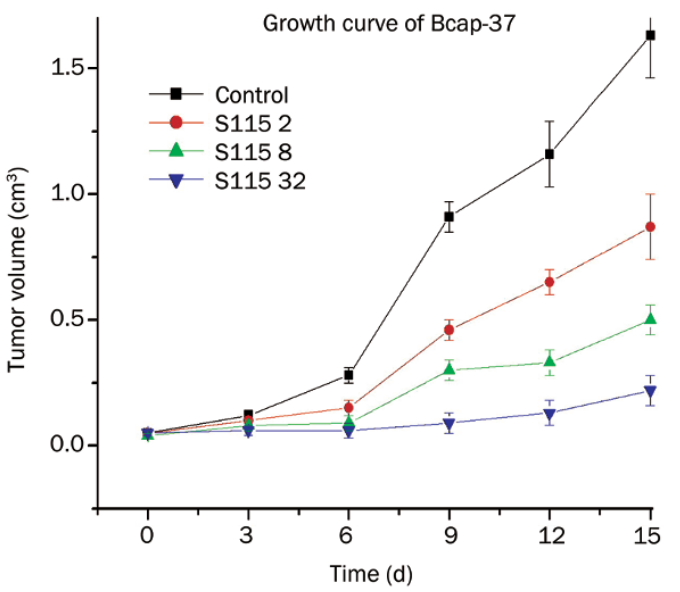

B

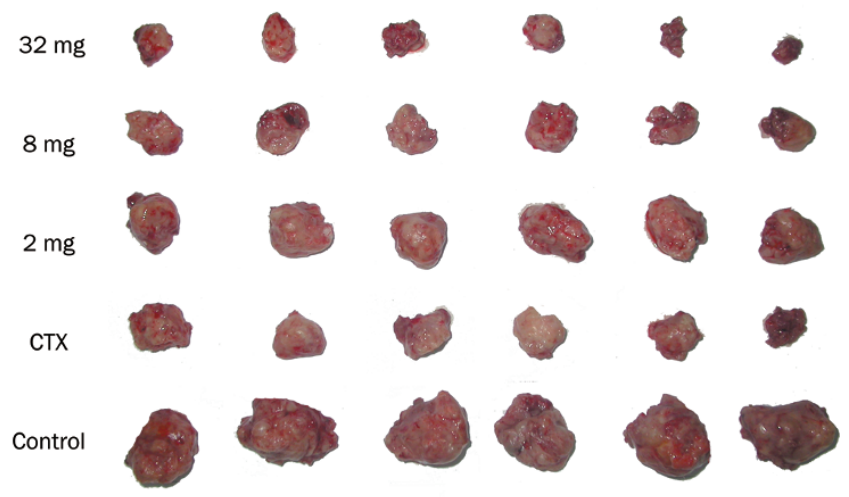

Figure 5. Inhibitory effects of multi-daily gavage of S115 on Bcap-37 tumor growth in xenografted Bcap-37-BALB/c nude mouse model. Bcap37 human breast cancer cells were injected into BALB/c nude mice. After solid tumors grew to about $100 \mathrm{~mm}^{3}$, mice were given multi-daily gavage of saline $(0.5 \mathrm{~mL} / \mathrm{d})$ or $\mathrm{S} 115$ (2, 8, or $32 \mathrm{mg} / \mathrm{kg})$ for $7 \mathrm{~d}$. (A) Tumor growth was measured by tumor volume and is graphed over time. (B) Images are isolated tumors from the mice from each group after $12 \mathrm{~d}$ of treatment. Data are presented as mean \pm SD. ( $n=6$ per group).

because thiourea and thiosemicarbazone have stronger lipotropy than urea and can permeate tissues more effectively. Some of these compounds have a strong anticancer activity. However, so far, no products based on these compounds have been approved for clinical purposes.

The anticancer activity is outstanding among all the thiourea compounds in vitro and in vivo. The inhibitory rate of S115 against tumors increases as the dose increases from $2 \mathrm{mg} / \mathrm{kg}$ to $32 \mathrm{mg} / \mathrm{kg}$, but there is no toxicity of S115 at these doses in mice. The therapeutic window of S115 is wide in thiourea compounds, suggesting the compound is safe to be used. The mechanism of action of S115 was discovered in thiourea compounds, and thus, we further explored the mechanism.

An investigation of S115 at the cellular and molecular levels was also conducted. S115 induced apoptosis in the human lung cancer cell line, $A 549 ; \mathrm{G}_{0}-\mathrm{G}_{1}$ phase transition was blocked after treatment with S115 for $24 \mathrm{~h}$. These results suggest that the anticancer effect of S115 is closely related to apoptosis induction and cell cycle blockade. We further found that ubiquitin and Tob2 were the differentially expressed genes. The mammalian BTG/Tob family is composed of six proteins, BTG1, BTG2/PC/Tis21, BTG3/ANA, BTG4/PC3B, Tob1/Tob, and Tob2. All the members of the BTG/Tob family have a conserved 104-106 amino acid area at the N-end. Biochemical and structural theories have shown that the conserved BTG structure involves protein-protein interactions. Tob1 and Tob2 proteins make up the Tob subfamily, and these proteins have larger C-end areas than the other members of the BTG family. Regarding functions, the BTG/Tob family can adjust cell growth and promote cell differentiation and maturity, which is also likely to be related to the injury and repair of DNA. In this way, this family is considered an anti-proliferative gene family ${ }^{[28,29]}$. It has been reported that BTG/Tob protein is degenerated by the ubiquitin-proteasome complex. The current experiments showed that the transcription of the ubiquitin gene was down-regulated in A549 cells exposed to S115, and that the protein expression of Tob2 increased, indicating the influence of S115 on the ubiquitin-proteasome system. Although the specific mechanism responsible for this activity remains unclear, it is possible that the anti-proliferative effects are via the proteins of the Tob2 subfamily that are degraded by the ubiquitin-proteasome system.

\section{Conclusion}

S115, a heteroaromatic thiosemicarbazone compound, exhibited anticancer activity in vitro and in vivo without inducing a significant loss of body weight and had a synergistic effect with cytotoxic compounds. S115-treated mice showed decreased tumor volume in a dose-dependent manner, with $42.0 \%$ to $81.8 \%$ inhibition; S115 induced apoptosis and cell cycle arrest in the $\mathrm{G}_{0}-\mathrm{G}_{1}$ phase. The inhibition of ubiquitinproteasome and the stimulation of Tob2 were also observed.

\section{Acknowledgements}

This work was funded by the Biomedicine Scientific and Technological Projects of Shanghai (\#10431900700). We thank Dr Yong-xiang WANG at Shanghai Jiao Tong University School of Pharmacy (Shanghai, China) for editing the manuscript.

\section{Author contribution}

Min-yu LIU, Ming YIN, and Quan-hai LIU designed the experiments; Min-yu LIU, Lin XIAO, and Li CAI performed the experiments; Min-yu LIU and Yu-qiong DONG drafted the manuscript; Yu-long YAO and Ying LIU edited the manuscript; Wei-xia XIONG analyzed the data.

\section{References}

1 Brown B, Harris R. Derivatives of $N$-(pyrid-2-yl)thiourea as root growth inhibitors. Pesticide Sci 1973; 4: 215-25.

2 Zheng W, Yates SR, Papiernik SK, Guo M. Transformation of herbicide propachlor by an agrochemical thiourea. Environ Sci Technol 2004; 38: 6855-60.

3 Pandey H, Ram V, Mishra L. Heterocyclic thioureas as pesticides 
A

\begin{tabular}{rccrrr}
\hline Group & Apoptosis (\%) & $\mathrm{G}_{0}-\mathrm{G}_{1}$ & $\mathrm{G}_{2}-\mathrm{M}$ & $\mathrm{S}$ & $\mathrm{G}_{2} / \mathrm{G}_{1}$ \\
\hline $\mathrm{O} \mathrm{h}$ & 7.59 & 46.09 & 7.46 & 46.45 & 2.03 \\
$3 \mathrm{~h}$ & 30.86 & 59.31 & 6.53 & 34.16 & 1.94 \\
$6 \mathrm{~h}$ & 74.35 & 78.94 & 13.24 & 7.82 & 1.94 \\
$12 \mathrm{~h}$ & 78.96 & 74.78 & 14.32 & 10.90 & 1.93 \\
$24 \mathrm{~h}$ & 78.94 & 78.76 & 14.33 & 6.91 & 1.90 \\
$48 \mathrm{~h}$ & 85.27 & 72.59 & 12.40 & 15.01 & 2.01 \\
\hline
\end{tabular}
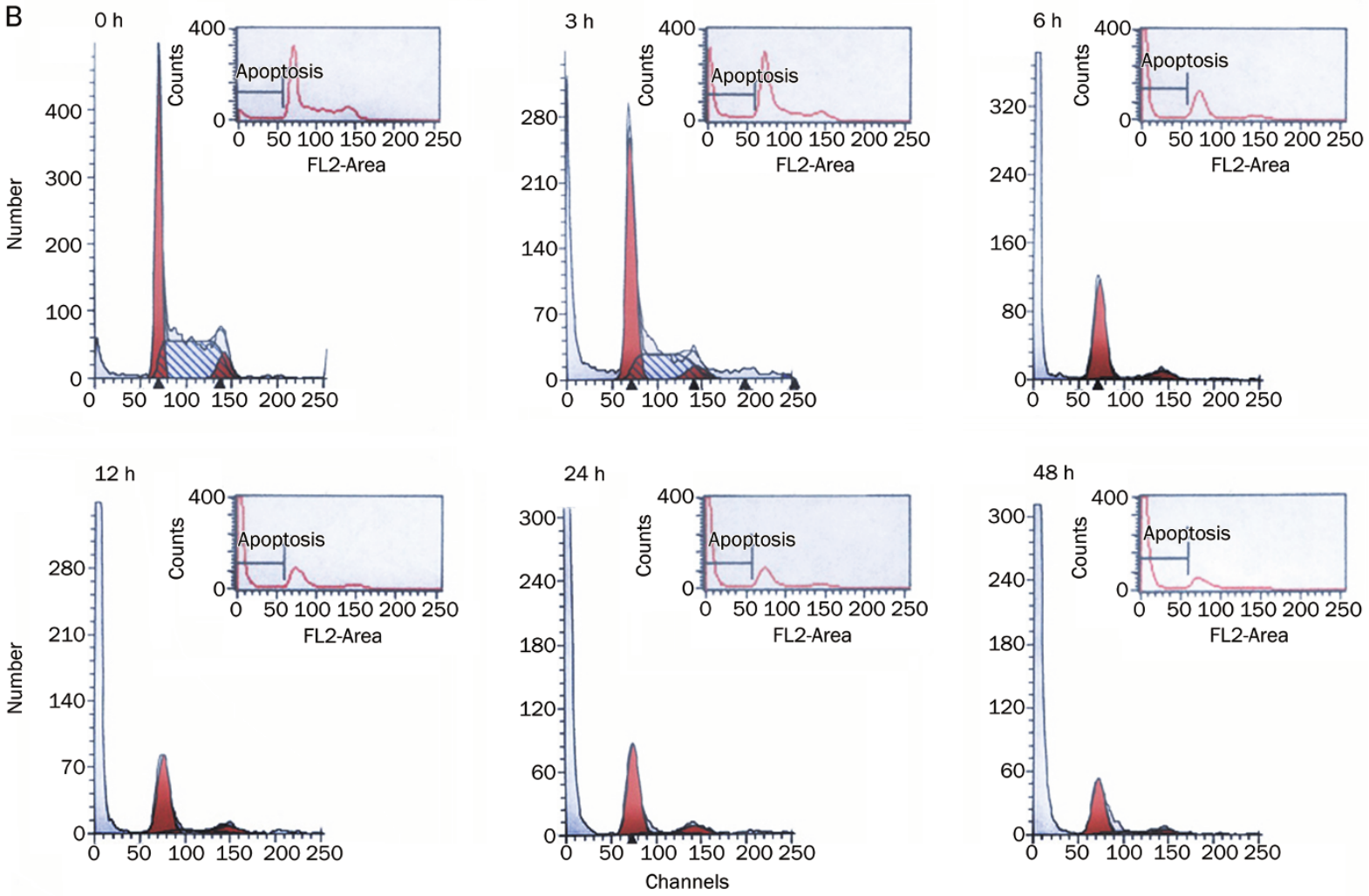

Figure 6. $\mathrm{S} 115(1.5 \mu \mathrm{mol} / \mathrm{L})$ promotes progressive apoptosis and $\mathrm{G}_{0}-\mathrm{G}_{1}$ cell cycle arrest in $\mathrm{A} 549$ human lung carcinoma cells (A). The apoptotic cells were stained with propidium iodide and the cell cycle distribution was evaluated using a flow cytometry (B).

1979.

$4 \mathrm{Ni} \mathrm{C}$, Yi C, Feng Z. Studies of syntheses and adsorption properties of chelating resin from thiourea and formaldehyde. J Appl Polymer Sci 2001; 82: 3127-32.

5 Takemoto Y. Development of chiral thiourea catalysts and its application to asymmetric catalytic reactions. Chem Pharm Bull 2010; 58: 593-601.

6 Susamma A, Mini VTE, Kuriakose A. Studies on novel binary accelerator system in sulfur vulcanization of natural rubber. J Appl Polymer Sci 2001; 79: 1-8.

7 Khan SA, Singh N, Saleem K. Synthesis, characterization and in vitro antibacterial activity of thiourea and urea derivatives of steroids. Eur J Med Chem 2008; 43: 2272-7.

8 Abbas SY, Sh El-Sharief MA, Basyouni WM, Fakhr IM, El-Gammal EW. Thiourea derivatives incorporating a hippuric acid moiety: Synthesis and evaluation of antibacterial and antifungal activities. Eur J Med Chem 2013; 64: 111-20.

9 Phetsuksiri B, Jackson M, Scherman H, McNeil M, Besra GS, Baulard
AR, et al. Unique mechanism of action of the thiourea drug isoxyl on Mycobacterium tuberculosis. J Biol Chem 2003; 278: 53123-30.

10 Manjula SN, Malleshappa Noolvi N, Vipan Parihar K, Manohara Reddy SA, Ramani V, Gadad AK, et al. Synthesis and antitumor activity of optically active thiourea and their 2-aminobenzothiazole derivatives: A novel class of anticancer agents. Eur J Med Chem 2009; 44: 29239.

11 Mehanna AS, Belani JD, Kelley CJ, Pallansch LA. Design, synthesis and biological evaluation of a series of thioamides as non-nucleoside reverse transcriptase inhibitors. Med Chem 2007; 3: 513-9.

12 Moorthy NS, Cerqueira NM, Ramos MJ, Fernandes PA. Aryl- and heteroaryl-thiosemicarbazones derivatives and its metal complexes: a pharmacological template. Recent Pat Anticancer Drug Discov 2013; 8: 168-82.

13 Xiong X, Liu H, Fu L, Li L, Li J, Luo X, et al. Antitumor activity of a new $\mathrm{N}$-substituted thiourea derivative, an EGFR signaling-targeted inhibitor against a panel of human lung cancer cell lines. Chemotherapy 2008; 54: 463-74. 


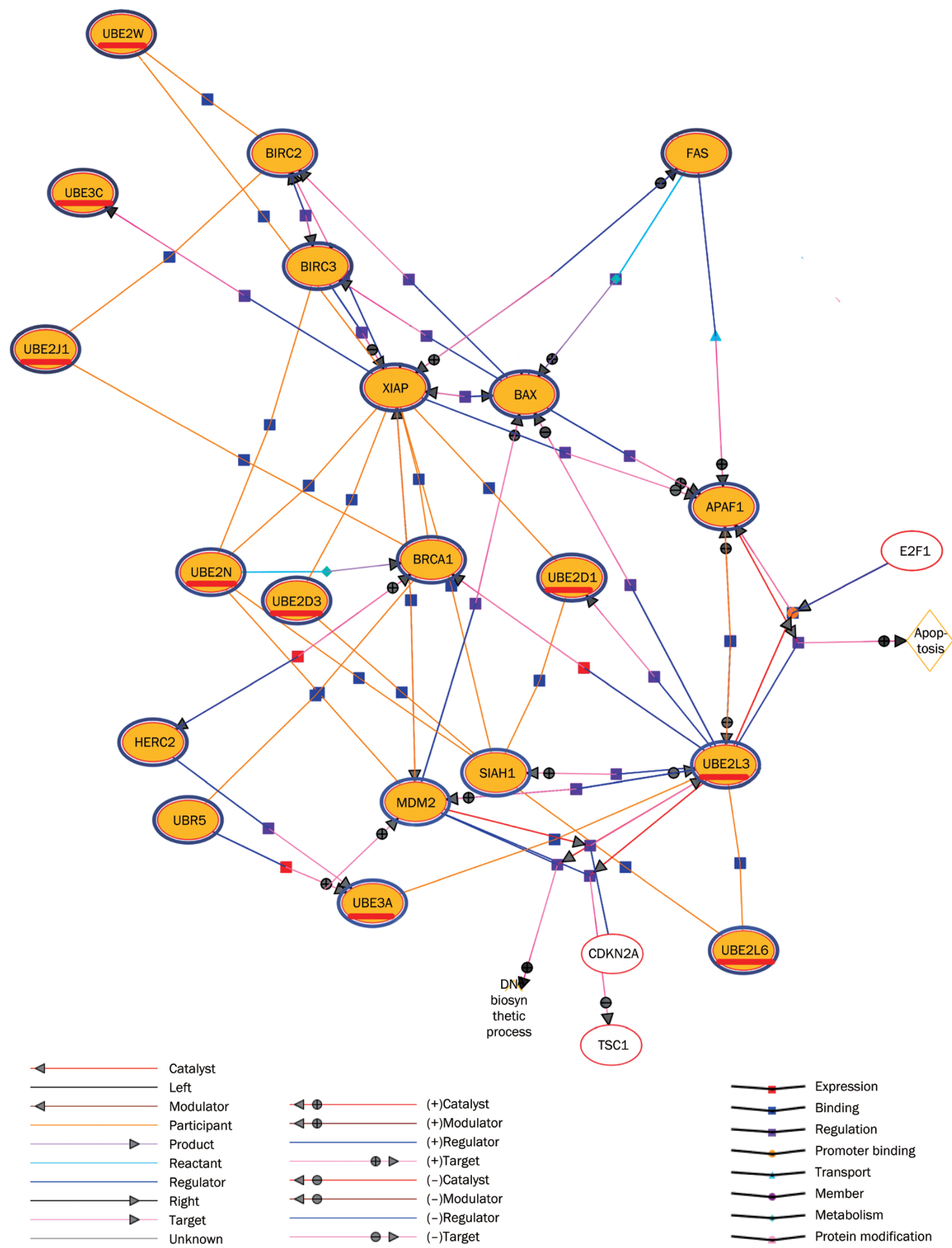

Figure 7. Changes in the gene expression of human non-small cell lung carcinoma A549 cells under the action of $1.5 \mu \mathrm{mol} / \mathrm{L}$ of S115 at different time points: $0,3,6,12,24,48$, and $72 \mathrm{~h}$ with 3 chips per point. The network of differentially expressed genes included those involved in the UPS obtained from microarray analysis. 
A

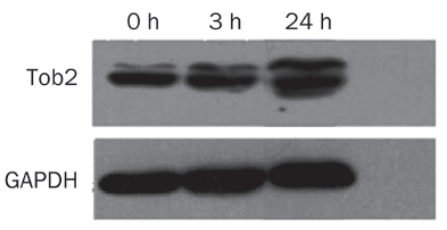

B

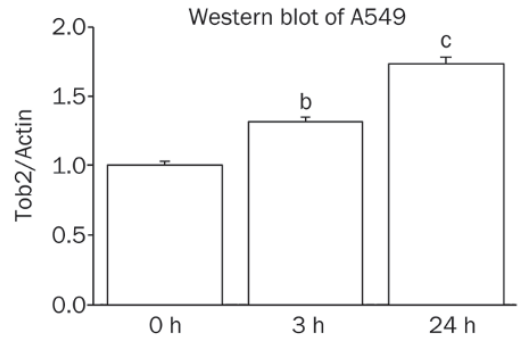

C

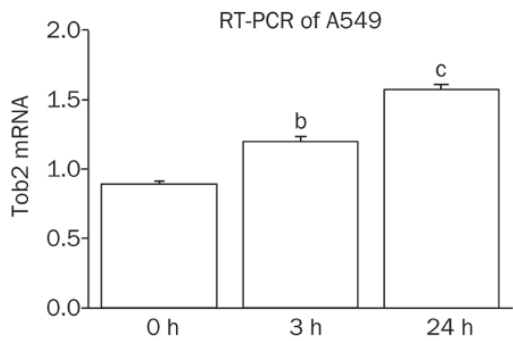

Figure 8. Tob2 status of the human non-small cell lung carcinoma A549 cell line under the action of $1.5 \mu \mathrm{mol} / \mathrm{L}$ of S115 measured at 3 points in time: 0,3 , and $24 \mathrm{~h}$. The status of Tob2 was upregulated by $\mathrm{S} 115$ as indicated by Western blot analysis and RT-PCR. ${ }^{b} P<0.05,{ }^{\circ} P<0.01$ vs $0 \mathrm{~h}$.

14 Huhtiniemi T, Suuronen T, Rinne VM, Wittekindt C, Lahtela-Kakkonen $\mathrm{M}$, Jarho $\mathrm{E}$, et al. Oxadiazole-carbonylaminothioureas as SIRT1 and SIRT2 inhibitors. J Med Chem 2008; 51: 4377-80.

15 Rao VA. Iron chelators with topoisomerase-inhibitory activity and their anticancer applications. Antioxid Redox Signal 2013; 18: 930-55. doi: 10.1089/ars.2012.4877.

16 Finch RA, Liu M, Grill SP, Rose WC, Loomis R, Vasquez KM, et al. Triapine (3-aminopyridine-2-carboxaldehyde-thiosemicarbazone): A potent inhibitor of ribonucleotide reductase activity with broad spectrum antitumor activity. Biochem Pharmacol 2000; 59: 983-91.

17 Jin Z. Addition in drug combination (author's transl). Acta Pharmacol
Sin 1980; 1: 70.

18 Soriano ML, Lenthall JT, Anderson KM, Smith SJ, Steed JW. Enhanced anion binding from unusual coordination modes of bis (thiourea) ligands in platinum group metal complexes. Chemistry 2010; 16 : 10818-31.

19 Yan K, Lok CN, Bierla K, Che CM. Gold (I) complex of N, $N^{\prime}$-disubstituted cyclic thiourea with in vitro and in vivo anticancer properties - potent tight-binding inhibition of thioredoxin reductase. Chem Commun 2010; 46: 7691-3.

20 Serda M, Kalinowski DS, Mrozek-Wilczkiewicz A, Musiol R, Szurko A, Ratuszna A, et al. Synthesis and characterization of quinoline-based thiosemicarbazones and correlation of cellular iron-binding efficacy to anti-tumor efficacy. Bioorg Med Chem Lett 2012; 22: 5527-31.

21 Hancock CN, Stockwin LH, Han B, Divelbiss RD, Jun JH, Malhotra SV, et al. A copper chelate of thiosemicarbazone NSC 689534 induces oxidative/ER stress and inhibits tumor growth in vitro and in vivo. Free Rad Biol Med 2011; 50: 110-21.

22 Choi BS, Alberti DB, Schelman WR, Kolesar JM, Thomas JP, Marnocha $\mathrm{R}$, et al. The maximum tolerated dose and biologic effects of 3-aminopyridine-2-carboxaldehyde thiosemicarbazone (3-AP) in combination with irinotecan for patients with refractory solid tumors. Cancer Chemother Pharmacol 2010; 66: 973-80.

23 Zhao Y, Ge CW, Wu ZH, Wang CN, Fang JH, Zhu L. Synthesis and evaluation of aroylthiourea derivatives of 4- $\beta$-amino-4'-O-demethyl-4desoxypodophyllotoxin as novel topoisomerase II inhibitors. Eur J Med Chem 2011; 46: 901-6.

24 Yao J, Chen J, He Z, Sun W, Xu W. Design, synthesis and biological activities of thiourea containing sorafenib analogs as antitumor agents. Bioorg Med Chem 2012; 20: 2923-9.

25 Xiong X, Liu H, Fu L, Li L, Li J, Luo X, et al. Antitumor activity of a new $\mathrm{N}$-substituted thiourea derivative, an EGFR signaling-targeted inhibitor against a panel of human lung cancer cell lines. Chemotherapy 2008; 54: 463-74.

26 Matsuno K, Ichimura M, Nakajima T, Tahara K, Fujiwara S, Kase H, et al. Potent and selective inhibitors of platelet-derived growth factor receptor phosphorylation. 1 . Synthesis, structure-activity relationship, and biological effects of a new class of quinazoline derivatives. J Med Chem 2002; 45: 3057-66.

27 Bohnsack BL, Gallina D, Kahana A. Phenothiourea sensitizes zebrafish cranial neural crest and extraocular muscle development to changes in retinoic acid and IGF signaling. PLoS One 2011; 6: e22991.

28 Du W, Mei QB. Ubiquitin-proteasome system, a new anti-tumor target. Acta Pharmacol Sin 2013; 34: 187-8.

29 Soh UJ, Dores MR, Chen B, Trejo J. Signal transduction by protease activated receptors. Br J Pharmacol 2010; 160: 191-203. 